SOME NEW BOUNDS FOR THE GENERALIZED TRIANGLE INEQUALITY

\title{
HOSSEIN DEHGHAN
}

Abstract. In this paper we present some new inequalities in normed linear spaces which much improve the triangle inequality. Our results refine and generalize the corresponding ones obtained by Mitani et al. [ On sharp triangle inequalities in Banach spaces, J. Math. Anal. Appl. 336 (2007) 1178-1186].

Mathematics subject classification (2010): Primary 47A30; Secondary 26D20.

Keywords and phrases: inequality, triangle inequality, norm inequality.

\section{REFERENCES}

[1] J. A. Clarkson, Uniformly convex spaces, Trans. Amer. Math. Soc. 40 (1936), 396-414.

[2] C. F. Dunkl And K. S. Williams, A simple norm inequality, Amer. Math. Monthly 71 (1964), $53-54$.

[3] H. HudziK And T. R. LAndes, Characteristic of convexity of Köthe function spaces, Math. Ann. 294 (1992), 117-124.

[4] M. Kato, K. S. SAito And T. TAmuRa, Sharp triangle inequality and its reverse in Banach spaces, Math. Ineqal. Appl. 10, 2 (2007), 451-460.

[5] W. A. Kirk and M. F. Smiley, Mathematical Notes: Another characterization of inner product spaces, Amer. Math. Monthly 71, 8 (1964), 890-891.

[6] L. Maligranda, Simple norm inequalities, Amer. Math. Monthly 113 (2006), 256-260.

[7] L. Maligranda, Some remarks on the triangle inequality for norms, Banach J. Math. Anal. 2, 2 (2008), 31-41.

[8] J. L. MASSERA AND J. J. SChAFFER, Linear differential equations and functional analysis I, Ann. of Math. 67 (1958), 517-573.

[9] K. Mitani, K. S. Saito, M. Kato And T. Tamura, On sharp triangle inequalities in Banach spaces, J. Math. Anal. Appl. 336 (2007), 1178-1186. 